\title{
Effects of Unconjugated Bilirubin on Bilirubin-UDP-Glucuronyl Transferase Activity in Liver of Newborn Rats
}

\author{
A. F. BAKKEN ${ }^{[24]}$ \\ Pediatric Research Institute and Institute of Medical Biochemistry, \\ University of Oslo, Norway
}

\begin{abstract}
Extract
The bilirubin-UDP-glucuronyl transferase (BGT) activity in liver of newborn rats was measured to determine if unconjugated bilirubin could be the trigger substance of glucuronyl transferase activity. Comparison was made among normal rats, newborn rats, and rats of mothers that had been given varying doses of unconjugated bilirubin during pregnancy.

Three groups of pregnant Wistar rats were used for the experiments. Group I received bilirubin by intravenous injection once a day during the last five days of pregnancy. Group II received a suspension of bilirubin by intraperitoneal injection during the sixteenth to twenty-first day of pregnancy. Group III served as controls.

Activity was determined by a modification of the method of LATHE and WALKER [14]. Total bilirubin was determined in the incubates according to the method of Fog and BAKKEN [9], while conjugated and unconjugated bilirubin were determined by methods described by Fog and BAKkEN [10].

BGT activity was measured as bilirubin conjugated per gram wet weight liver per hour (table I). Normal newborn rats were unable to conjugate bilirubin at birth, while newborn rats of mothers that had been injected with $150 \mathrm{mg}$ bilirubin for more than 24 hours showed BGT activity at birth. Newborn rats of mothers that had received $150 \mathrm{mg}$ bilirubin less than 24 hours before delivery showed no BGT activity in liver at birth, but the enzyme was activated earlier after birth in these rats than it was in normal rats.

The results show that unconjugated bilirubin triggers UDP-glucuronyl transferase and thus functions as an activator for excretion of bilirubin.
\end{abstract}

\section{Speculation}

The finding that unconjugated bilirubin functions as a trigger for bilirubin-UDP-glucuronyl transferase activity does not explain the molecular mechanism that leads to increased enzyme activity. Further studies are needed to show whether the increased level of activity after birth is due to a new production of ribonucleic acid (RNA), to activation of a protein already present, or to inactivation or withdrawal of an inhibitor. The possible relation between the level of bilirubin in the serum and the conjugating capacity in the newborn should also be studied. 


\section{Introduction}

Normally, bilirubin-UDP-glucuronyl transferase (BGT) is inactive in the liver of the fetus and the newborn infant $[3,14]$. The delayed activation of $B G T$, however, could be due to inhibitors irt utero [3, 17], although conjugated bilirubin has been observed in serum at birth $[1,8,11,19]$. It is unlikely that estrogen inhibitors regulate the activity of BGT at birth, since the concentration of the inhibitors is constant.

That bilirubin alone could trigger UDP-glucuronyl transferase activity is supported by the finding that conjugated bilirubin is present at birth in infants with erythroblastosis fetalis. These circumstances suggest that these infants are able to conjugate earlier than normal newborn infants. The excretory capacity for bilirubin is unexplained. The intrauterine hyperbilirubinemia probably acts as the trigger substance for BGT.

In the present study, a comparison was made between the activity of BGT in the liver of normal rats, newborn rats, and rats loaded with varying doses of unconjugated bilirubin during intrauterine life.

\section{Materials and Methods}

Pregnant, six-month-old Wistar rats weighing between 200 and $350 \mathrm{~g}$ and fed a Pellet diet were used for the experiments. Rats loaded with bilirubin [22] and normal rats were kept mixed.

\section{Group I}

During the last five days of pregnancy an $0.5 \mathrm{ml}$ intravenous injection of $200 \mathrm{mg}$ bilirubin in $0.4 \%$ $\mathrm{Na}_{2} \mathrm{CO}_{3}$ (anhydr.) at $\mathrm{pH}$ 10.9-11.0 was given once a day. The solution had been filtered and kept in the dark until used.

\section{Group II}

During the sixteenth to twenty-first day of pregnancy, $3 \mathrm{ml}$ of a bilirubin suspension $(10$ to $50 \mathrm{mg}$ bilirubin per $\mathrm{ml}$ in a mixture of equal volumes of $0.4 \%$ $\mathrm{Na}_{2} \mathrm{CO}_{3}$ [anhydr.] and $5 \mathrm{mM}$ EDTA [etylendiamintetracetate] $\mathrm{pH}$ 10.2-10.4) was injected intraperitoneally.

\section{Group III}

Control animals were given $3 \mathrm{ml}$ of the mixture of $\mathrm{Na}_{2} \mathrm{CO}_{3}$ and EDTA, with bilirubin omitted.

\section{Preparation of the Tissue and Determination of Enzyme} Activity

Following decapitation, the livers were removed immediately and placed in the homogenizing medium, $0.154 \mathrm{M} \mathrm{KCl}$ containing $3.210^{-4} \mathrm{M} \mathrm{KHCO}_{3}$ [5] at $+4^{\circ}$. Homogenates were prepared by grinding one gram of a mixture of liver from offspring of one mother in $9 \mathrm{ml}$ homogenizing medium in an ice bath. The livers from either two or three newborn rats were mixed, depending on the weight. If less than one gram of liver was used, the volume of the homogenizing medium was reduced accordingly. The mixture was homogenized in a Potter-Elvehjem homogenizer for ten minutes at a constant speed of $80 \mathrm{rpm}$. Incubation was performed as described by LATHE and WALKER [14], with the exception that the bilirubin solution was dissolved in $10 \mathrm{ml}$ of a mixture of equal volumes of $0.4 \% \mathrm{Na}_{2} \mathrm{CO}_{3}$ (anhydr.) and $5 \mathrm{mM}$ EDTA. The $\mathrm{pH}$ was adjusted to 11 by adding dropwise $0.1 \mathrm{~N} \mathrm{NaOH}$. This bilirubin solution was filtered and kept in the dark until use. Activity was reported as $\mu \mathrm{g}$ of bilirubin conjugated/g wet weight of liver $/ \mathrm{h}(\mu \mathrm{g} / \mathrm{gmw} / \mathrm{h})$.

Total bilirubin in the incubates was determined by the method of FOG and BAKKeN [9] and conjugated and unconjugated bilirubin were determined by direct spectrophotometry [10], inasmuch as the azo-methods for bilirubin determination in in vitro determination of glucuronide formation were not recommended [2]. Total bilirubin in sera from pregnant rats was determined by the method of JENDRASSIK and GRoF [13] as modified by FoG [7]. Bilirubin in serum of newborn rats was not measured.

\section{Results}

Newborn and one-day-old normal rats showed no hepatic BGT-activity. At two days of age, activity varied from 0 to $60 \mu \mathrm{g} / \mathrm{gmw} / \mathrm{h}$. Subsequently, the activity increased to $225 \mu \mathrm{g} / \mathrm{gmw} / \mathrm{h}$ and was stabilized at about $275 \mu \mathrm{g} / \mathrm{gmw} / \mathrm{h}$ after fourteen days.

Total bilirubin in sera of untreated pregnant rats varied from 0.2 to $0.5 \mathrm{mg}$ bilirubin per $100 \mathrm{ml}$.

\section{Group I}

BGT-activity in the newborn rats of mothers that had been loaded with $200 \mathrm{mg}$ of bilirubin intravenously once a day during the last five days of pregnancy did not differ from that in normal newborn rats.

Total bilirubin in the sera of these pregnant rats did not exceed $0.6 \mathrm{mg} / 100 \mathrm{ml}$.

\section{Group II}

BGT-activity at birth in rats whose mothers had received $150 \mathrm{mg}$ of bilirubin more than 24 hours before 
Table I. Bilirubin-UDP-glucuronyl transferase activity in liver of rats

\begin{tabular}{|c|c|c|c|c|c|c|c|c|c|c|c|c|}
\hline \multirow[b]{2}{*}{ Days after birth } & \multicolumn{12}{|c|}{$\mu \mathrm{g}$ bilirubin conjugated/g wet weight liver/h } \\
\hline & 0 & 1 & 2 & 3 & 4 & 5 & 8 & 9 & 14 & 21 & 28 & Adults \\
\hline \multirow[t]{5}{*}{ No load } & 0 & 0 & 0 & 90 & 144 & 180 & 150 & 84 & 132 & 276 & 288 & 248 \\
\hline & 0 & 0 & 30 & 100 & 160 & 182 & 180 & 198 & 380 & 384 & 270 & 260 \\
\hline & 0 & 0 & 60 & & & 210 & 265 & 240 & 368 & 276 & & 280 \\
\hline & 0 & 0 & & & & 264 & 278 & 180 & 180 & 372 & & 292 \\
\hline & & & & & & 216 & 210 & 165 & 320 & & & 316 \\
\hline Offsprings from 17 & & & & & & 230 & 216 & 180 & & & & 330 \\
\hline mothers & & & & & & & 180 & & & & & 552 \\
\hline Bilirubin given less than 24 hours & 0 & 60 & 120 & 178 & 285 & & & & & & & \\
\hline before birth & 0 & 110 & 120 & 136 & 310 & & & & & & & \\
\hline Offsprings from 9 & 0 & 110 & & 144 & & & & & & & & \\
\hline mothers & 0 & & & 180 & & & & & & & & \\
\hline \multirow{3}{*}{$\begin{array}{l}\text { Bilirubin given more than } 24 \text { hours } \\
\text { before birth }\end{array}$} & 0 & 24 & 80 & 72 & 56 & 252 & 450 & 486 & 225 & 195 & & \\
\hline & 12 & 46 & 140 & 144 & 90 & 252 & 450 & 504 & 265 & 390 & & \\
\hline & 25 & 86 & 140 & 180 & 160 & & & & 282 & & & \\
\hline \multirow{6}{*}{$\begin{array}{l}\text { Offsprings from } 21 \\
\text { mothers }\end{array}$} & 35 & 102 & 178 & 240 & 172 & & & & 300 & & & \\
\hline & 37 & & & & 200 & & & & 345 & & & \\
\hline & 60 & & & & 238 & & & & & & & \\
\hline & 62 & & & & & & & & & & & \\
\hline & 70 & & & & & & & & & & & \\
\hline & 75 & & & & & & & & & & & \\
\hline
\end{tabular}

birth varied from 0 to $78 \mu \mathrm{g} / \mathrm{gmw} / \mathrm{h}$. After 24 hours, values ranged from 25 to $100 \mu \mathrm{g} / \mathrm{gmw} / \mathrm{h}$, with an average value of $65 \mu \mathrm{g} / \mathrm{gmm} / \mathrm{h}$. The maximal value, $335 \mu \mathrm{g} /$ $\mathrm{gmw} / \mathrm{h}$, was reached at eight to ten days of age. Total bilirubin in the sera of these pregnant rats varied from 1.3 to $2.6 \mathrm{mg} / 100 \mathrm{ml}$.

BGT activity in offspring of the control rats did not differ from that found in normal newborn rats.

Newborn rats whose mothers were loaded with bilirubin less than 24 hours prior to birth showed no activity in liver at the time of birth; activity was detectable on the second day of life $(0-110 \mu \mathrm{g} / \mathrm{gmw} / \mathrm{h})$. After four days of life, activity was stabilized at about $300 \mu \mathrm{g} /$ $\mathrm{gmw} / \mathrm{h}$.

BGT activity of newborn rats whose mothers received 50 and $100 \mathrm{mg}$ of bilirubin intraperitoneally one to five days before birth did not differ from that found in the liver of normal newborn rats.

Total bilirubin in the serum of these pregnant rats varied from 0.6 to $1.2 \mathrm{mg} / 100 \mathrm{ml}$. There was no correlation between BGT activity in the newborn and the level of bilirubin in the mothers when the level was higher than $1.3 \mathrm{mg} / 100 \mathrm{ml}$.

\section{Discussion}

The present study shows a possible mechanism for the activation of the bilirubin conjugating system. Excretion of bilirubin was not studied.

The results show that BGT is inactive in normal newborn rats. Activity of this enzyme is measurable a few days after birth; however, newborn rats of mothers with hyperbilirubinemia conjugated bilirubin at birth. Although the delayed activation of BGT in the normal newborn has been reported to be caused by estrogens $[12,17]$, we do not believe that these inhibitors are important, since BGT is active in utero in infants with erythroblastosis fetalis [1]. The level of estrogens is no lower in these infants as compared to normal subjects. In addition, estrogen inhibitors of BGT affect only intact cells and not the enzyme in homogenates [15]. This fact must mean that the estrogens inhibit the transport of bilirubin through the cell wall and not the enzyme activity per se. Therefore, homogenates were used in this study to eliminate any error resulting from a failure of bilirubin to penetrate intact cell wall. Activity of BGT is related to the concentration of un- 
conjugated bilirubin, according to Schmid et al. [19]. These authors were unsuccessful in an attempt to stimulate glucuronidation of o-aminophenol by intraperitoneal loading with sodium antralinate. Later, LESTER and SCHMid and others $[6,16,21]$ showed the importance of using bilirubin as a substrate for studies of BGT.

Table I shows the levels of BGT activity in the liver of normal rats, newborn rats, and rats of mothers loaded with varying amounts of bilirubin. Newborn rats of mothers loaded with an intraperitoneal injection of $150 \mathrm{mg}$ of bilirubin more than 24 hours before delivery showed BGT activity at birth. The unconjugated bilirubin served as a depot from which bilirubin escaped at such a rate that the liver of the pregnant rat was unable to conjugate all of it. The level of bilirubin in serum increased to 1.3 to $2.6 \mathrm{mg} / 100 \mathrm{ml}$, four times greater than that in the control rats. Since unconjugated bilirubin in serum can pass through the placenta [18] there was a parallel increase in the level of bilirubin in serum in the rat fetus. This increase in the fetus acted as a trigger for BGT activity.

Levels of bilirubin were not measured in serum of newborn rats used in these studies. The experiments were designed to identify a difference between the BGT activity in the normal newborn rat and the newborn rat whose mother was loaded with bilirubin. A difference was noted even in the newborn rats whose mothers were loaded less than 24 hours before delivery. These rats did not show any BGT activity at birth, but their livers were able to conjugate bilirubin earlier after birth than were those from normal rats. These results indicate that the enzyme activating process had started in utero even in these cases, but that 24 hours are too short a time for the process of stimulation to be completed.

These studies, therefore, show that unconjugated bilirubin appears to act as a trigger for glucuronyl transferase activity.

\section{Summary}

Pregnant Wistar rats were loaded with bilirubin during the last days of pregnancy. The newborn rats of mothers that had been given $150 \mathrm{mg}$ of bilirubin by intraperitoneal injection more than 24 hours before birth were able to conjugate bilirubin at birth. However, normal newborn rats did not show this ability until about two days after birth. Newborn rats of mothers loaded with $150 \mathrm{mg}$ bilirubin less than 24 hours before birth were unable to conjugate bilirubin at birth, but developed this ability earlier in life than did normal newborn rats.

It appears, therefore, that unconjugated bilirubin is a trigger substance for bilirubin-UDP-glucuronyl transferase activity in the newborn period.

\section{References and Notes}

1. BAKKen, A.F. and FOG, J.: Bilirubinconjugation in the newborn. Lancet $i: 1280$ (1967).

2. Boerth, R.G.; Blatr, A.H. and Spratt, J.L.: Limitations in the determination of invitro bilirubin glucuronid formation. J. Lab. clin. Med. 65: 475483 (1965).

3. Brown, A.K.; Zúlzer, W.W. and Burnett, H.N.: Studies on the neonatal development of the glucuronide conjugating system. J. clin. Invest. 37: 332-340 (1958).

4. Dunn, P.M.: Obstructive and haemolytic disease of the newborn. Arch. Dis. Childh. 38: 54-61 (1963).

5. Dutton, G.J. and Storey, D.E.: Uridine compounds in glucuronide acid metabolism. Biochem. J. 57: 275-283 (1954).

6. FloodgaArd, H.J. and Brodersen, R.: Bilirubin glucuronide formation in developing guinea pig liver. Scand. J.clin. Lab. Invest. 19: 149-155 (1967).

7. FoG, J.: Determination of bilirubin in serum as alkaline 'azobilirubin'. Scand.J.clin. Lab. Invest. 10: 241-245 (1958).

8. FoG, J.: Serumfarge og bilirubin i ikteriske sera. Thesis, Tanum, Oslo (1960).

9. FoG, J. and BAKKEN, A.F.: Absorptivity of alkaline bilirubin and bilirubin in serum. Scand.J.clin. Lab. Invest. 20: 70-72 (1967).

10. FoG, J. and BAKKeN, A.F.: Conjugated and unconjugated bilirubin determined in icteric sera by direct spectrophotometry. Scand.J. clin. Lab. Invest. 20: 88-92 (1967).

11. Harris, L.E.; Farrell, F.J.; Shorter, R.G.; Banner, E.A. and Mathieson, D. R.: Conjugated serumbilirubin in erythroblastosis foetalis. Proc. Mayo Clin. 37: 574-581 (1962).

12. Hsia, D.Y-Y.; Rrabow, S. and Dowben, R.M.: Inhibition of glucuronyl transferase by steroid hormones. Arch. Biochem. 103: 181-185 (1963).

13. JeNDRASSIK, L. und GROF, P.: Vereinfachte photometrische Methoden zur Bestimmung des Blutbilirubins. Biochem. Z. 297: 81-89 (1938).

14. Lathe, G.H. and Walker, M.: The synthesis of bilirubinglucuronide in animal and human liver. Biochem.J. 70: 705-712 (1958).

15. Lathe, G.H. and Walker, M.: Inhibition of glucuronide conjugation in rat slices by human pregnancy and neonatal serum and steroids. Quart.J. exp. Physiol. 43: 257-265 (1958). 
16. Lester, R. and Schmid, R.: Bilirubin metabolism. New Engl.J. Med. 270: 779-786 (1964).

17. Nemeth, A. M. : Initiation of enzyme formation by birth. Ann. N.Y.Acad. Sci. III: 199-202 (1963).

18. Sahenker, S.; Bashore, R.A. and Smith, F.: Bilirubin disposition in fetal monkeys; in Bilirubin metabolism (ed. Bouchier, I.A.D. and Billing, B.H.) (Blackwell, Oxford/Edinburgh 1967).

19. Schmid, R.; Buckingham, S.; Mendilla, G. A. G. and Hammaker, L.: Bilirubin metabolism in the fetus. Nature, Lond. 183: 1823-1824 (1959).
20. Stempfel, R.; Broman, B.; Escardo, F.E. and ZetTerstrøm, R.: Obstructive jaundice complicating hemolytic disease of the newborn. Pediatrics 17: 471-481 (1956).

21. Tombrnson, G.A. and YAFFE, S.J.: The formation of bilirubin and p-nitrophenol glucuronides by rabbit liver. Biochem.J. 99: 507-512 (1966).

22. Sigma Chemical Company, St. Louis, Mo.

23. Supported by grant No.E 303-8 from the Norwegian Council for Science and the Humanities.

24. BAKKen, M.D., Pediatric Research Institute, Rikshospitalet, Oslo 1 (Norway). 